\title{
Workload Assessment with Ovako Working Posture Analysis System (OWAS) in Japanese Vineyards with Focus on Pruning and Berry Thinning Operations
}

\author{
Yin Yin Nwe', Shigeki Toyama ${ }^{2}$, Masei Akagawa ${ }^{3}$, Masaaki Yamada ${ }^{3}$, Kouki Sotta ${ }^{4}$, \\ Takashi Tanzawa ${ }^{4}$, Chiko Kikuchi ${ }^{5}$ and Isao Ogiwara ${ }^{1,3 *}$ \\ ${ }^{1}$ United Graduate School of Agricultural Science, Tokyo University of Agriculture and Technology, Fuchu 183-8509, Japan \\ ${ }^{2}$ Graduate School of Engineering, Tokyo University of Agriculture and Technology, Koganei 184-8588, Japan \\ ${ }^{3}$ Graduate School of Agriculture, Tokyo University of Agriculture and Technology, Fuchu 183-8509, Japan \\ ${ }^{4}$ JA Fruits Yamanashi, Koshu 404-0045, Japan \\ ${ }^{5}$ Tokyo Metropolitan Agriculture and Forestry Research Center, Tachikawa 190-0013, Japan
}

A questionnaire survey was conducted in Yamanashi Prefecture in the course of adapting a wearable robotic suit, which was originally developed for assisting human care (Yonetake and Toyama, 2005), to agriculture. Among various farm operations, farmers had a heavy workload when grape berry thinning followed by cluster shaping and pruning, and $58 \%$ of farmers hoped to buy a wearable agri-robot suit that may support their arms, legs, and back. Using the main Ovako Working Posture Analysis System (OWAS), physical workload was evaluated during pruning and berry thinning in vineyards on a slope and flatland; pruning was a heavier workload than berry thinning irrespective of the farm topography and, for both operations, working on the slope was a heavier workload. According to the second OWAS working posture percentages for the relative proportions of the postures of different body parts, workers have to maintain a static posture by raising the arms at or above shoulder level for more than $\mathbf{7 0 \%}$ of the total working time in berry thinning. The arm posture in berry thinning was classified as $\mathrm{AC} 3$ and corrective measures are necessary as soon as possible. In the OWAS analysis system, although pruning was evaluated to have a higher level of physical stress than berry thinning, farmers felt that it is a lighter workload because it involves various postures, such as walking and sitting, whereas in berry thinning the farmer has to maintain the same posture by raising the arms and farmers especially felt arm fatigue while berry thinning. These results suggested that a mechanical support system is necessary to reduce the workload of grape farmers. Thus, in Japanese grape production, a wearable agri-robot suit focused on a support system for the back, arms and legs with free and rapid movement of the wearer might be an alternative solution to reduce the workload of grape farmers.

Key Words: OWAS analysis, physical stress, questionnaire survey.

\section{Introduction}

Recently, the Japanese society has been aging while its birth rate continues to decrease. In 2010, of the total population of 128.1 million, the agricultural workforce was 2.6 million people, of which 1.6 million $(65.61 \%)$ were over 65 years old. Older workers are barred from retiring due to the lack of young laborers in the agricultural sector. The intensive labor on family farms is one of the reasons why it attracts few young successors (Morinaga, 2001). Farm operations in Japan have been

Received; January 30, 2012. Accepted; May 2, 2012.

* Corresponding author (E-mail: ogiwara@cc.tuat.ac.jp). only partly mechanized due to the small farm size and topographical conditions of the mountainous country. Farm work includes physically demanding tasks such as lifting and carrying heavy loads, poor work postures, repetitive movements and vibration (Perkio-Makela and Hentila, 2005). Older farmers want support systems that would facilitate them to continue working, and the introduction of effective mechanical systems in field management has become a necessity.

Yonetake and Toyama (2005) developed a wearable robot suit for nursing care (Fig. 1) and tried to adapt it for agriculture (Toyama and Yamamoto, 2009). The potential of this robot suit to assist the farmer was investigated in various field management tasks, such as 


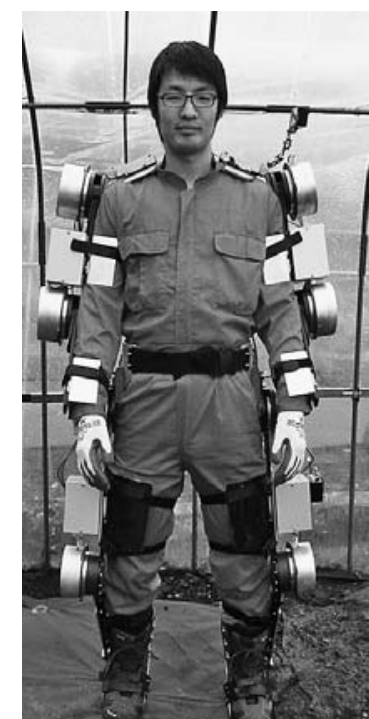

Fig. 1. The wearable agri-robot suit No. 8 developed by Toyama and Yamamoto (2009).

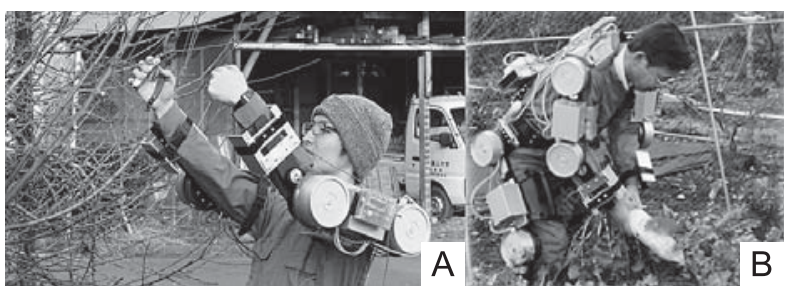

Fig. 2. Field demonstration of the wearable agri-robot suit in fruit tree pruning (A) and radish harvesting (B).

radish harvesting and fruit tree pruning operations (Fig. 2) (Ogiwara et al., 2010). As a result, the wearable robot suit reduced the workload of the operator by supporting his/her arms and legs; however, posture changes needed to be speeded up to adapt it to agricultural operations.

High-grade fruit is among the main items used as presents in Japan. Because of this, the Japanese demand fruits of good appearance as well as quality suitable for presents. In Japan, table grapes (Vitis spp.) account for about $87 \%$ of total grape production followed by $11 \%$ for wine, $1.4 \%$ for juice, and $0.1 \%$ for canned fruit. High quality grape production requires very intensive field management (about 4,500 annual hours per hectare) to attain large and regular-sized berries, optimal cluster size and compactness, and good coloration (Ando, 2006). To achieve high quality grapes, berry thinning and cluster shaping are the most labor-demanding management tasks that cause the major workloads in grape production. In Kyoho (V.labruscana cv. Kyoho) production, berry thinning and cluster shaping consume approximately $25 \%$ of the total working hours for all field management practices (Shiraishi, 2006); however, it is quite difficult to perform berry thinning and cluster shaping automatically or mechanically; therefore, new tech- niques to reduce the workload and to improve labor productivity are required in the intensive grape production system. An improved wearable agri-robot suit may be good news for Japanese grape farmers; however, insufficient information was available on the recent status of the Japanese grape industry, workload of local grape production systems, and whether farmers really wanted the robot suit.

Ergonomic approaches for estimating workload and physical stress may be grouped as follows: (a) questionnaire and interview methods for recording the feelings of the person doing a job, (b) physiological or direct methods to measure organic changes in the person doing a job, for example measuring blood pressure and heart rate etc., and (c) methods based on observations, such as the Ovako Working Posture Analysis System (OWAS), Task Recording and Analysis on Computer (TRAC), Posture, Activity, Tools and Handling (PATH), Rapid Upper Limb Assessment (RULA), Rapid Entire Body Assessment (REBA), Postural Loading on the Upper Body Assessment (LUBA), Computer-Based Postural Workload Evaluation System Based on a MacroPostural Classification Scheme (PLAS), etc.

In agriculture, OWAS is probably the best method for studying the postures involved in whole-body work. OWAS provides the user with an overall estimate of the appropriateness/inappropriateness of the work postures used (Tuure, 1992). Therefore in this study, the questionnaire survey and OWAS were intended to estimate farmers' physical stress while pruning and berry thinning in their vineyards located on a slope and flatland, with the purpose of improving the wearable agri-robot suit.

\section{Materials and Methods}

\section{Questionnaire survey}

The survey was conducted in 2009 to investigate the workload in grape production and the opinions of grape farmers about the wearable agri-robot suit. A total of 102 grape farmers from Yamanashi Prefecture participated in this survey. Background parameters of the participants are presented in Table 1; their age and height, and daily working hours and working experiences in grape production. The questionnaire about the workload included: (1) the field management task that makes the farmer feel most tired, i.e., the hardest field management task among various field management practices in grape production, (2) the most stressed body part after berry thinning and cluster shaping, and (3) opinion about the wearable agri-robot suit, i.e., whether the robot suit is necessary to reduce the workload in grape production.

\section{Working posture analysis}

Based on the results of the survey, working postures in pruning and berry thinning on a slope and flatland were evaluated using OWAS, which is a simple and systematic method to analyze working posture by 
Table 1. Background parameters of the participants.

\begin{tabular}{lcc}
\hline \hline & $\mathrm{N}^{2}=102$ & \\
\hline Variable & Mean $\pm \mathrm{SD}$ & Range (minimum-maximum) \\
\hline Age (years) & $55 \pm 10$ & $31-85$ \\
Height $(\mathrm{cm})$ & $169 \pm 7$ & $147-183$ \\
Working hr/day & $9 \pm 2$ & $4-13$ \\
Working experience (years) & $24 \pm 6$ & $5-30$ \\
\hline
\end{tabular}

${ }^{\mathrm{z}}$ Number of survey participants.

\begin{tabular}{|c|c|c|c|c|c|c|c|c|c|c|c|}
\hline \multirow[t]{4}{*}{ Back } & \multirow{4}{*}{$\begin{array}{ll}1 & \text { Straight } \\
2 & \text { Bent forward } \\
3 & \text { Twisted or bent sidervays } \\
4 & \text { Bent and twisted }\end{array}$} & 1 & 1 & 1 & 1 & 1 & 1 & 1 & 1 & 1 & 1 \\
\hline & & 1 & 1 & 1 & 2 & 2 & 2 & 2 & 2 & 3 & 3 \\
\hline & & 1 & 1 & 2 & 2 & 2 & 3 & 3 & 3 & 3 & 3 \\
\hline & & 1 & 2 & 2 & 3 & 3 & 3 & 3 & 4 & 4 & 4 \\
\hline \multirow[t]{3}{*}{ Arms } & \multirow{3}{*}{$\begin{array}{l}1 \text { Both arms below shoulder level } \\
2 \text { One arm at or above shoulder level } \\
3 \text { Both arms at or above shoulder level }\end{array}$} & 1 & 1 & 1 & 1 & 1 & 1 & 1 & 1 & 1 & 1 \\
\hline & & 1 & 1 & 1 & 2 & 2 & 2 & 2 & 2 & 3 & 3 \\
\hline & & 1 & 1 & 2 & 2 & 2 & 2 & 2 & 3 & 3 & 3 \\
\hline \multirow[t]{7}{*}{ Legs } & \multirow{7}{*}{$\begin{array}{l}1 \text { Sitting } \\
2 \text { Standing with both legs straight } \\
3 \text { Standing with one leg straight } \\
4 \text { Standing or squatting with both legs bent } \\
5 \text { Standing or squatting with one leg bent } \\
6 \text { Kneeling on one or both knees } \\
7 \text { Walking or moving }\end{array}$} & 1 & 1 & 1 & 1 & 1 & 1 & 1 & 1 & 1 & 2 \\
\hline & & 1 & 1 & 1 & 1 & 1 & 1 & 1 & 1 & 2 & 2 \\
\hline & & 1 & 1 & 1 & 2 & 2 & 2 & 2 & & 3 & 3 \\
\hline & & 1 & 2 & 2 & 3 & 3 & 3 & 3 & 4 & 4 & 4 \\
\hline & & 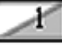 & 2 & 2 & 3 & 3 & 3 & 3 & 4 & 4 & 4 \\
\hline & & 1 & 1 & 2 & 2 & 2 & 3 & 3 & 3 & 3 & 3 \\
\hline & & 1 & 1 & 1 & 1 & 1 & 1 & 1 & 1 & 2 & 2 \\
\hline
\end{tabular}

Fig. 3. Action Category (AC) score levels 1 to 4 in Ovako Working Posture Analysis System (OWAS) based on the time spent for each body posture (Mattila and Vilkki, 2003).

observing the work being carried out. This method focuses on three body parts; the back, arms and legs. The main OWAS classification system of postures is based on the risk assessment of musculoskeletal disorders and the physical load on the musculoskeletal system. The action category (AC) indicates the urgency and priority of corrective measures. The second classification system is based on the time spent in different postures for each body part. This system examines the relative postures of the back, arms, and legs during the observation period. The postures for each are summed and when the relative proportion of a certain posture during the observation period exceeds the fixed limits, the action category changes from lower to higher (Mattila and Vilkki, 2003). This indicates that the urgency for corrective action is increasing (Fig. 3).

The study site was Yamanashi Prefecture, which produces about $24 \%$ of total grapes in Japan. Participants were full-time farmers who were both healthy and well experienced in grape growing. Forty farmers (3 for pruning on a slope, 4 for pruning on the flatland, 18 for berry thinning on a slope, and 15 for berry thinning on the flatland) participated in this study.

Pruning and berry thinning video clips were recorded under normal working condition in the vineyards. Both working postures and tasks were recorded at the same time. For data analysis, OWAS data analysis support software, a program created by the National Agriculture and Food Research Organization (Tateishi and Kobayashi, 2009. registration number: NARO A-19), was used. Firstly, recorded video clips were converted into photographs. After that, working postures were evaluated at 10-second intervals, for an observation period of 20 minutes using OWAS data analysis support software (Juul-Kristensen et al., 1997; Mattila and Vilkki, 2003; Mattila et al., 1993). The working postures were classified into action categories (AC) 1 to 4 according to the main and second OWAS classification systems.

\section{Results}

\section{Questionnaire survey}

The results of question No. 1, the hardest field management tasks in grape production, are shown in Figure 4, namely berry thinning (85\%), cluster shaping $(52 \%)$, and pruning (35\%). The results of question No. 2 , the most stressed body parts after berry thinning and cluster shaping, are shown in Figure 5. The farmers felt most fatigue in their arms $(88.2 \%)$, followed by the neck $(83.3 \%)$ and back $(74.3 \%)$ after berry thinning and cluster shaping. The results of question No. 3 , if the robot suit is necessary or not to reduce the workload in grape production, are shown in Figure $6 ; 58.0 \%$ of farmers wanted to buy the robot suit. 


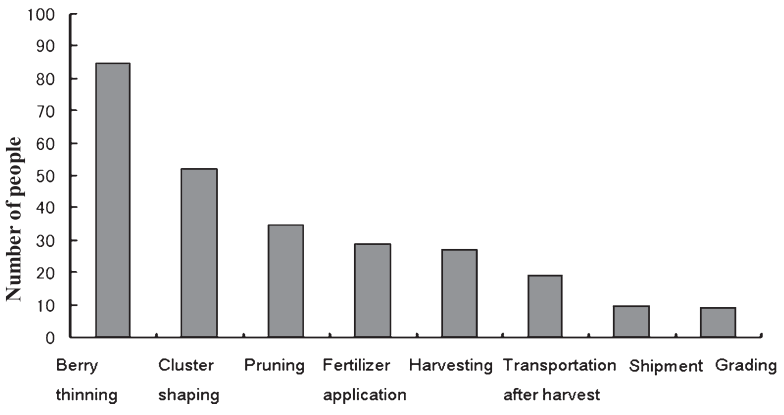

Fig. 4. The hardest field management operations causing heavy workloads in grape production in Japan. (102 participant farmers chose multiple answers from the questionnaire.)

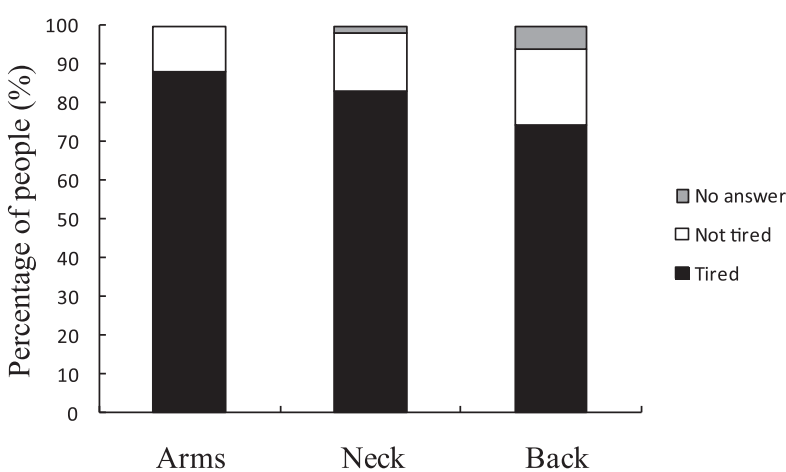

Fig. 5. Percentage of grape farmers who felt fatigue in the arms, neck, and back after berry thinning and cluster shaping. (102 participant farmers chose multiple answers from the questionnaire.)
Working posture analysis using OWAS

The average AC frequency percentages according to the main classification system for pruning and berry thinning on a slope and flatland are presented in Table 2. Pruning tended to have a heavier workload than berry thinning because the average values of AC2 to AC4 in pruning were higher than those of berry thinning. When the workload in berry thinning between the slope and the flatland was compared, average values of AC2 and AC3 were found to be higher for the slope than on the flatland, and a similar tendency was observed in pruning.

In Table 3, the results of average AC frequency percentages in pruning and berry thinning according to the second classification system are presented in detail. Working postures while pruning were observed to differ

Table 2. Frequency (\%) of OWAS action category (AC) 1 to 4 for corrective measures in pruning and berry thinning in vineyards on the slope and flatland.

\begin{tabular}{llcccc}
\hline \multicolumn{1}{c}{ Operation } & (topography) & $\mathrm{AC1}^{\mathrm{z}}$ & $\mathrm{AC2}^{\mathrm{y}}$ & $\mathrm{AC}^{\mathrm{x}}$ & $\mathrm{AC}^{\mathrm{w}}$ \\
\hline \multirow{3}{*}{ Pruning } & (slope) & 55.0 & 13.2 & 4.3 & 27.5 \\
& (flatland) & 83.0 & 13.2 & 2.8 & 1.0 \\
& Average & 69.0 & 13.2 & 3.6 & 14.3 \\
\hline \multirow{3}{*}{ Berry thinning } & (slope) & 95.0 & 3.7 & 1.3 & 0 \\
& (flatland) & 98.7 & 1.3 & 0 & 0 \\
& Average & 96.9 & 2.5 & 0.7 & 0 \\
\hline
\end{tabular}

${ }^{z}$ Corrective measures are not necessary.

y Corrective measures are necessary in the near future.

${ }^{x}$ Corrective measures are necessary as soon as possible.

${ }^{\mathrm{w}}$ Corrective measures are necessary immediately.

Table 3. OWAS working posture percentages for the relative proportions of the postures of different body parts in pruning and berry thinning.

\begin{tabular}{lccccc}
\hline \hline & \multicolumn{2}{c}{ Pruning } & & \multicolumn{2}{c}{ Berry thinning } \\
\cline { 2 - 2 } \cline { 5 - 6 } & $\mathrm{N}^{\mathrm{z}}=7$ & $\mathrm{AC}^{\mathrm{y}}$ & & $\mathrm{N}^{\mathrm{z}}=33$ & $\mathrm{AC}^{\mathrm{y}}$ \\
\hline Number of postures & 554 & & & 1999 \\
\hline Back & 74.3 & 1 & & 97.1 & 1 \\
Straight & 8.8 & 1 & & 2.9 & 1 \\
Bent forward, backward & 0.6 & 1 & 0 & 1 \\
Twisted or bent sideways & 16.3 & 2 & 0 & 1 \\
Bent and twisted & & & & \\
Arms & 41.6 & 1 & 13.5 & 1 \\
Both arms below shoulder level & 36.5 & 2 & 13.3 & 1 \\
One arm at or above shoulder level & 21.9 & $1-2$ & 73.2 & 3 \\
Both arms at or above shoulder level & & & & \\
Legs & 0 & 1 & 0 & 1 \\
Sitting & 56.0 & 1 & 90.6 & 2 \\
Standing with both legs straight & 1.0 & 1 & 0.6 & 1 \\
Standing with one leg straight & 6.1 & $1-2$ & 0.4 & 1 \\
Standing or squatting with both legs bent & 16.5 & 2 & 0.4 & 1 \\
Standing or squatting with one leg bent & 12.0 & 1 & 0 & 1 \\
Kneeling on one or both knees & 8.4 & 1 & 8.0 & 1 \\
Walking or moving & & & & \\
\hline
\end{tabular}

z Number of survey participants.

${ }^{y}$ Action category. 
Table 4. OWAS working posture percentages at different body parts in pruning in vineyards on the slope and flatland.

\begin{tabular}{|c|c|c|c|c|}
\hline & $\mathrm{AC}^{\mathrm{y}}$ & $\begin{array}{l}\text { Slope } \\
\mathrm{N}^{z}=3\end{array}$ & $\begin{array}{c}\begin{array}{c}\text { Flatland } \\
\mathrm{N}^{\mathrm{z}}=4\end{array}\end{array}$ & $\begin{array}{c}\text { Average } \\
\mathrm{N}^{\mathrm{z}}=7\end{array}$ \\
\hline Number of postures & & 276 & 832 & 554 \\
\hline \multicolumn{5}{|l|}{ Back } \\
\hline Straight & 1 & 58.8 & 89.8 & 74.3 \\
\hline Bent forward, backward & 1 & 8.8 & 8.8 & 8.8 \\
\hline Twisted or bent sideways & 1 & 0.7 & 0.4 & 0.6 \\
\hline Bent and twisted & $1-2$ & 31.7 & 0.9 & 16.3 \\
\hline \multicolumn{5}{|l|}{ Arms } \\
\hline Both arms below shoulder level & 1 & 31.8 & 51.4 & 41.6 \\
\hline One arm at or above shoulder level & 2 & 42.8 & 30.2 & 36.5 \\
\hline Both arms at or above shoulder level & 2 & 25.4 & 18.4 & 21.9 \\
\hline \multicolumn{5}{|l|}{ Legs } \\
\hline Sitting & 1 & 0 & 0 & 0 \\
\hline Standing with both legs straight & 1 & 40.1 & 71.8 & 56.0 \\
\hline Standing with one leg straight & 1 & 1.5 & 0.4 & 1.0 \\
\hline Standing or squatting with both legs bent & 1 & 9.1 & 3.0 & 6.1 \\
\hline Standing or squatting with one leg bent & $1-2$ & 25.2 & 8.0 & 16.5 \\
\hline Kneeling on one or both knees & 1 & 17.9 & 6.3 & 12.0 \\
\hline Walking or moving & 1 & 6.2 & 10.5 & 8.4 \\
\hline
\end{tabular}

${ }^{\mathrm{z}}$ Number of survey participants.

y Action category.

from those of berry thinning. The farmers had to work for $97.1 \%$ of their working time with a straight back and $2.9 \%$ bending their back forward or backward in berry thinning compared to $74.3 \%$ and $8.8 \%$ in pruning, respectively. Moreover, other postures of the back; twisting or bending sideways and bending and twisting were not found in berry thinning compared to $0.6 \%$ and $16.3 \%$ in pruning, respectively. In the case of arm postures, farmers worked for $13.5 \%$ of the total working time with both arms below shoulder level, $13.3 \%$ with one arm at or above shoulder level and $73.2 \%$ with both arms at or above the shoulder level in berry thinning compared to $41.6 \%, 36.5 \%$ and $21.9 \%$ in pruning, respectively. Arm posture in berry thinning was classified as AC3 compared to AC1-2 in pruning. For leg postures, farmers had to work $90.6 \%$ of the total working time with both legs straight, classified as AC2 in berry thinning, whereas $56 \%$ and classified as $\mathrm{AC} 1$ in pruning. Moreover, each posture percentage of standing with one leg straight, standing or squatting with both legs bent, standing or squatting with one leg bent, and kneeling on one or both knees in berry thinning was less than $1 \%$, which was much lower for the last three postures than in pruning. Whereas standing or squatting with both legs bent and with one leg bent were classified as $\mathrm{AC} 1$ in berry thinning, they were $\mathrm{AC} 1-2$ and $\mathrm{AC} 2$, respectively, in pruning.

The results of the relative proportions (\%) of the postures by each body part in pruning are presented in detail with $\mathrm{AC}$ indices in Table 4 according to the second classification system. Considerable differences in working postures and $\mathrm{AC}$ were observed between the slope and flatland. Farmers decreased the straight back posture $(58.8 \%)$ and increased the back bent and twisted posture $(31.7 \%)$ on the slope. For the legs, farmers worked in more variable postures on the slope than on the flatland, such as kneeling $(17.9 \%$ versus $6.3 \%$, respectively), standing with one leg bent $(25.2 \%$ vs. $8.0 \%)$, standing with both legs bent $(9.1 \%$ vs. $3.0 \%)$, and standing with one leg straight (1.5\% vs. $0.4 \%)$.

In Table 5, the results in berry thinning are presented likewise. No differences in AC were observed between berry thinning on the slope and flatland. When the percentages of postures of the back and arms were compared, no large difference was observed between the slope and flatland. For leg postures, farmers worked for $87.2 \%$ of the total working time with both legs straight on the slope compared to $94.2 \%$ on the flatland. The percentage of walking or moving was a little larger on the slope than on the flatland.

\section{Discussion}

The results of the questionnaire survey showed that the farmers were tired due to the intensive labor requirement in grape production. They felt that the most stressful field management task was berry thinning followed by cluster shaping and pruning (Fig. 4). They especially felt fatigue in the arms followed by the neck and back (Fig. 5). Approximately $60 \%$ were willing to buy the wearable agri-robot suit to reduce the workload of the various field managements required to produce high quality grapes (Fig. 6); therefore, improvements to 
Table 5. OWAS working posture percentages at different body parts in berry thinning in vineyards on the slope and flatland.

\begin{tabular}{|c|c|c|c|c|}
\hline & $\mathrm{AC}^{\mathrm{y}}$ & $\begin{array}{c}\text { Slope } \\
\mathrm{N}^{\mathrm{z}}=18\end{array}$ & $\begin{array}{c}\text { Flatland } \\
\mathrm{N}^{2}=15\end{array}$ & $\begin{array}{c}\text { Average } \\
\mathrm{N}^{\mathrm{z}}=33\end{array}$ \\
\hline Number of postures & & 2466 & 1531 & 1999 \\
\hline \multicolumn{5}{|l|}{ Back } \\
\hline Straight & 1 & 96.3 & 97.9 & 97.1 \\
\hline Bent forward, backward & 1 & 3.7 & 2.1 & 2.9 \\
\hline Twisted or bent sideways & 1 & 0 & 0 & 0 \\
\hline Bent and twisted & 1 & 0 & 0 & 0 \\
\hline \multicolumn{5}{|l|}{ Arms } \\
\hline Both arms below shoulder level & 1 & 15.8 & 11.1 & 13.5 \\
\hline One arm at or above shoulder level & 1 & 12.7 & 13.9 & 13.3 \\
\hline Both arms at or above shoulder level & 3 & 71.5 & 75.0 & 73.2 \\
\hline \multicolumn{5}{|l|}{ Legs } \\
\hline Sitting & 1 & 0 & 0 & 0 \\
\hline Standing with both legs straight & 2 & 87.2 & 94.2 & 90.6 \\
\hline Standing with one leg straight & 1 & 0.1 & 1.1 & 0.6 \\
\hline Standing or squatting with both legs bent & 1 & 0.7 & 0 & 0.4 \\
\hline Standing or squatting with one leg bent & 1 & 0.7 & 0 & 0.4 \\
\hline Kneeling on one or both knees & 1 & 0 & 0 & 0 \\
\hline Walking or moving & 1 & 11.3 & 4.7 & 8.0 \\
\hline
\end{tabular}

${ }^{\mathrm{z}}$ Number of survey participants.

y Action category.

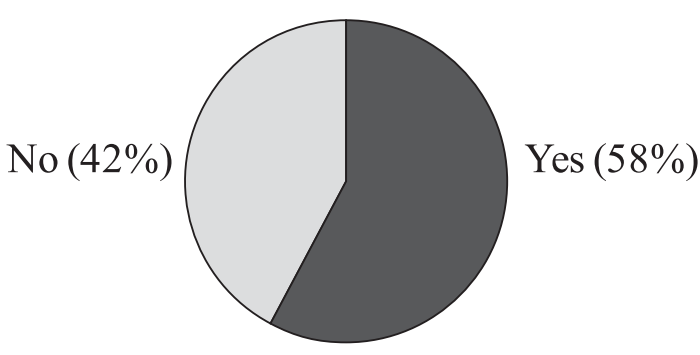

Fig. 6. Percentage of grape farmers grouped by their demand for the wearable agri-robot suit. (102 participant farmers chose only one answer, Yes or No, from the questionnaire.)

the wearable agri-robot suit are needed to make it adaptable for agriculture.

On the other hand, the OWAS results indicated that pruning was a heavier workload than berry thinning. In pruning on the slope, $27.5 \%$ of the total working postures were classified as AC4 (Table 2) and corrective measures were necessary immediately. Higher percentages of poor working postures (AC2, AC3, and $\mathrm{AC} 4)$ were observed more frequently in vineyards on a slope than on the flatland for both pruning and berry thinning (Table 2). Working in vineyards on a slope tended to be more difficult due to the uneven ground surface, and the farmers needed to bend their back and legs quite often, resulting in poor or harmful postures for them (Figs. 7 and 8). These results are consistent with those of Akagawa et al. (2010) in which $95.5 \%$ of grape farmers felt tired after working on a slope. Pruning was characterized by various postures and berry thinning mostly had the same posture (Table 3 ); therefore, when

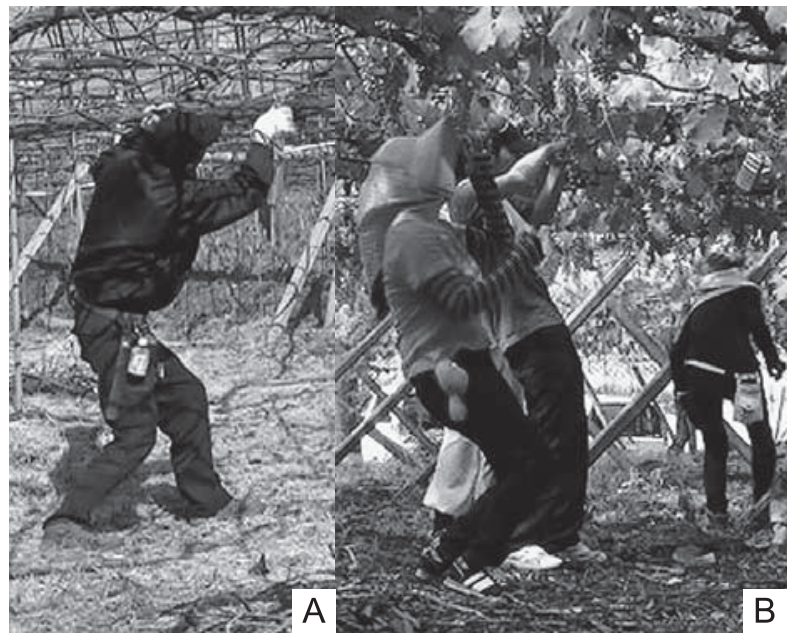

Fig. 7. Poor working postures in grape vine pruning (A) and berry thinning (B) in sloping vineyards.

pruning on a slope, the farmers felt especially tired in their back and legs.

The AC in berry thinning was estimated to have low physical stress in the main OWAS (Table 2) because the system defines the movements of body segments around the lower back, shoulder, and lower extremities ( $\mathrm{Li}$ and Buckle, 1999). Second OWAS working posture percentages for the relative proportions of the postures of different body parts in berry thinning were then investigated (Table 3 ). In berry thinning, the farmer had to maintain the same posture by raising the arms at or above shoulder level for more than $70 \%$ of the total 


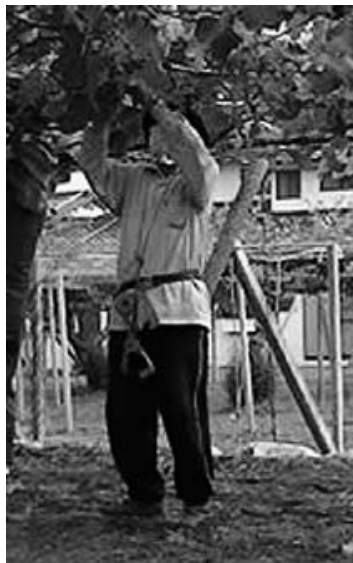

Fig. 8. Normal working posture in grape berry thinning in a flatland vineyard.

working time, which was classified as AC3 (Table 3), and corrective measures were necessary as soon as possible. Berry thinning was evaluated to have a higher level of physical stress from the viewpoint of the percentage and AC value for arm posture. Moreover, the questionnaire results suggested that berry thinning had the heaviest workload (Fig. 4), which caused more physical stress, whereas in pruning, the farmers worked in various postures such as walking and sitting while choosing branches to remove, and they bent their back and legs quite often.

In Japan, the horizontal trellis system is often used for grape production because it can minimize damage by typhoons. Usually the height of the trellis does not match the height of farmers because most vineyards were established by their grandparents. If a farmer is taller than the trellis height, he/she has to work by bending the legs and back, and if shorter than the trellis height, he/she has to work by stretching the neck and legs. The horizontal trellis system is assumed to be one of the factors causing poor working postures and increasing physical stress on grape growers.

To reduce physical stress, actions should be considered to change the horizontal trellis to another suitable planting system. Breeding new grape cultivars with fewer fruits per cluster may also be a solution to reduce the workload because berry thinning is not necessary for such cultivars. In addition, developing the wearable agrirobot suit is also one of the alternative ways to reduce the workload of grape farmers. Suggestions should be made to improve the wearable agri-robot suit focusing on support of the arms, back, and legs. Developments are necessary so that the wearer may move freely and quickly. Safety is also essential as the farmers work in vineyards on a slope, where postures are characterized by a bent back and frequent walking and moving. On the flatland, farmers kept their arms above shoulder level for a longer time, but on the slope, they were seen starting the task after having confirmed their safe balance.

The intensive labor requirement in grape production is one of the main factors causing heavy workload for farmers. The farmers undergo physical stress when pruning grapevines in various postures, whereas they feel more physical stress when lifting their arms above the shoulder for a long time in berry thinning in the same posture. OWAS was found to be an effective tool to investigate workload in various postures, but a questionnaire survey is also necessary to access workloads as a pre-survey. To reduce the heavy workload, adapting the wearable agri-robot suit for agriculture might be necessary. Improvements should be made focusing on support of the arms, back and legs with free and rapid movement of the wearer.

\section{Literature Cited}

Akagawa, M., G. Yamamoto, K. Sotta, T. Tanzawa, C. Kikuchi, S. Toyama and I. Ogiwara. 2010. A survey to analyze the workload in the production of grapes and the need for wearable agri-robot suit in assisting farm labor. Hort. Res. (Japan) 9 (Suppl.1): 79 (In Japanese).

Ando, T. 2006. The Japanese personality and the use of horticultural products. p. 4-8. In: Japan. Soc. Hort. Sci. (ed.). Horticulture in Japan. Shoukadoh Publication, Kyoto.

Juul-Kristensen, B., N. Fallentin and C. Ekdahl. 1997. Criteria for classification of posture in repetitive work by observation methods: A review. International Journal of Industrial Ergonomics 19: 397-411.

Li, G. and P. Buckle. 1999. Current techniques for assessing physical exposure to work-related musculoskeletal risks, with emphasis on posture-based methods. Ergonomics 42: 674695.

Mattila, M. and M. Vilkki. 2003. OWAS methods. p. 26.1-26.13. In: W. Karwowski and W. S. Marras (eds.). Occupational ergonomics: principles of work design. Principles and applications in engineering series. CRC press, Boca Raton, London, New York, and Washington, D.C.

Mattila, M., W. Karwowski and M. Vilkki. 1993. Analysis of working postures in hammering tasks on building construction sites using the computerized OWAS method. Applied Ergonomics 24: 405-412.

Morinaga, K. 2001. Grape production in Japan. p. 38-52. In: M. K. Papademetriou and F. J. Dent (eds.). Grape production in the Asia-Pacific region. FAO., Bangkok.

Ogiwara, I., G. Yamamoto, T. Araki. C. Kikuchi, S. Kawamura, S. Ninomiya and S. Toyama. 2010. Practical use of wearable agri-robot suit for assisting farm work. Hort. Res. (Japan) 8 (Suppl.1): 387 (In Japanese).

Perkio-Makela, M. and H. Hentila. 2005. Physical work strain of dairy farming in loose housing barns. International Journal of Industrial Ergonomics 35: 57-65.

Shiraishi, M. 2006. Grape. p. 42-50. In: Japan. Soc. Hort. Sci. (ed.). Horticulture in Japan. Shoukadoh Publication, Kyoto.

Toyama, S. and G. Yamamoto. 2009. Development of wearableagri-robot mechanism for agricultural work. International Conference on Intelligent Robots and Systems, 2009: 58015806 (Abstr.).

Tuure, V. 1992. Determination of physical stress in agricultural work. International Journal of Industrial Ergonomics 10: 275 284.

Yonetake, U. and S. Toyama. 2005. Development of the ultrasonic motor-powered assisted suit system. Proceedings of International Association of Science and Technology for Development. (485) Biomechanics: 18-23 (Abstr.). 